\title{
Urbanization affects plant flowering phenology and pollinator community: effects of water availability and land cover
}

Kaesha Neil ${ }^{1}$, Jianguo $\mathrm{Wu}^{1,2^{*}}$, Christofer Bang $^{1}$ and Stanley Faeth ${ }^{3}$

\begin{abstract}
Introduction: Climate change and urbanization have been shown to alter plant phenology. However, a mechanistic understanding of these changes in flowering phenology and associated pollinator communities is lacking. Thus, this study was designed to examine finer scale flowering phenological patterns and driving processes in an arid urban ecosystem. Specifically, we tested the effect of water availability and land cover type on the flowering phenology of brittlebush (Encelia farinosa) and investigated the arthropod pollinator community associated with brittlebush.
\end{abstract}

Methods: The fieldwork was carried out as part of a larger community ecology experiment following a factorial nested design. We chose three land cover types, each of which had three replicates, resulting in a total of nine sites. For water availability manipulations, 60 genetically different 5-gallon potted plants were placed on the ground within each site. Pan-trapping was used to collect potential pollinators.

Results: Our results showed that water availability did not produce significant differences in flowering phenology. However, brittlebush planted in mesiscaped urban sites bloomed later, longer, and at a higher percentage than those planted in desert remnant sites and desert fringe sites. Furthermore, desert remnant sites were significantly lower in pollinator abundance than desert fringe sites. Pollinator richness varied over time in all land cover types.

Conclusions: This study provides empirical evidence that land cover type, which is strongly correlated to temperature, is the primary cause for altered flowering phenology of brittlebush in the Phoenix area, although water availability may also be important. Moreover, land cover affects total abundance of bee pollinators.

Keywords: Urban ecology; Urban heat island effects; Flowering phenology; Land cover; Pollinators

\section{Introduction}

Phenological changes (the timing of environment-influenced developmental events) associated with urbanization and global climate change have been observed worldwide for bird migration, amphibian reproduction, plant leafing and flowering, and arthropod appearance and development (Buyantuyev and Wu 2009; Grimm et al. 2008; Neil et al. 2010; Neil and Wu 2006; Walther et al. 2002). For plants in particular, earlier and, to a lesser extent, later blooming of plants over time and within urban areas compared to

\footnotetext{
* Correspondence: jingle.wu@asu.edu

${ }^{1}$ School of Life Sciences, Arizona State University, P.O. Box 874501, Tempe,

AZ 85287-4501, USA

${ }^{2}$ School of Sustainability, Global Institute of Sustainability, Arizona State

University, Tempe, AZ 85287, USA

Full list of author information is available at the end of the article
}

rural areas have been reported in western Europe (Fitter and Fitter 2002; Hepper 2003; Mimet et al. 2009; Roetzer et al. 2000), China (Lu et al. 2006), and North America (Primack et al. 2004; Schwartz and Reiter 2000; Zhao and Schwartz 2003). All of these studies have attributed the change in flowering phenology to higher temperatures due to the urban heat island effect. Two of the studies empirically tested temperature effects (Mimet et al. 2009; Ziska et al. 2003) but did not separate effects by increased temperature from those by increased carbon dioxide. None of the studies looked at finer scale spatial effects such as land cover. Other factors in urban ecosystems, e.g., pollution (Honour et al. 2009), have also been investigated for their effect on flowering phenology (Neil and $\mathrm{Wu} 2006)$.

\section{实}


Abundance and richness of bees have also been studied extensively across the world (Cane et al. 2006; Eremeeva and Sushchev 2005; Matteson et al. 2008; McFrederick and LeBuhn 2006; McIntyre and Hostetler 2001; Pauw 2007; Tommasi et al. 2004) to understand the effects of global climate change and urbanization on pollinators. This research shows a general decrease of bees in urban areas, although some species, particularly cavity-nesting ones, respond positively. Besides hummingbirds (Arizmendi et al. 2007; Calvino-Cancela 2006), there is a paucity of data on other animal pollinators such as bats, mammals, reptiles, birds, and other arthropod pollinators. In addition to abundance and richness of pollinators, how pollinator synchrony with plants is being modified due to global climate change and urbanization is of interest. Models (Memmott et al. 2007) and studies of synchronized phenology (Gordo and Sanz 2005; Parmesan 2006; Walther et al. 2002) have found a general trend towards less synchrony between historically interdependent species.

The objectives of this study were (1) to identify finescale phenological patterns of brittlebush by empirically testing the effects of water availability and land cover type on the flowering phenology of brittlebush (Encelia farinosa) and (2) to investigate arthropod pollinator community associated with brittlebush in different land cover types and over time in the Phoenix metropolitan region, Arizona, United States. Brittlebush was chosen because it is a native Sonoran desert shrub, is commonly used in landscaping across the Phoenix metropolitan area, and appears to vary in flowering phenology across the city. Because previous studies have indicated that brittlebush is a winter-spring blooming plant that responds to both water availability and temperature as cues for flowering (Bowers and Dimmitt 1994), we hypothesized that both water availability and land cover types (which strongly affect temperature) would affect the timing, length, and percent of plants in flower. Additionally, we hypothesized that pollinator abundance and richness would vary by land cover type and over time. Whereas general bee abundance and richness has been studied in cities worldwide, we wanted to understand how the entire pollinator community is synchronized with the flowering of brittlebush in different land cover types.

\section{Methods}

\section{Study area, plant, and sites}

The Phoenix metropolitan region is in the northern portion of the Sonoran Desert which has a warm (mean summer high temperature of $40^{\circ} \mathrm{C}$ ) and dry (mean annual precipitation of $193 \mathrm{~mm}$ ) climate with two distinct wet seasons - one in winter and the other in summer (Bowers and Dimmitt 1994). Urban development has been concentrated in the flat and broad Salt River Valley (Jenerette and Wu 2001; Luck and Wu 2002; Wu et al. 2010). This region has a distinct densely developed urban core with decreasing urban and residential density further away from the core. However, development does not reflect a concentric zone or multinucleus pattern. Instead, agriculture and desert land patches are interspersed within an urban and residential matrix (Buyantuyev et al. 2010; Wu et al. 2010).

Brittlebush (E. farinosa) is a common Sonoran desert drought-deciduous shrub in the Compositae family found on washes, flats, and slopes in scrubland (Bowers and Dimmitt 1994; Epple 1995; U.S. Forest Service 2003). It has greenish-gray, simple leaves covered in white hairs growing on brittle many-branched stems. Pubescence varies greatly depending on local spatiotemporal moisture patterns but has a genetic component. Drier areas and times result in denser pubescence to reduce water loss but result in compromised photosynthetic ability. They have dense rounded canopies and can grow as much as $1.5 \mathrm{~m}$ tall with shallow roots $(40 \mathrm{~cm})$. Brittlebush blossoms consist of bright yellow daisy-like rays and disks up to $5 \mathrm{~cm}$ in diameter; however, the disk florets can be purple in some populations. The flowers develop on tall panicles that grow above the leaf canopy. It blooms February through May but may bloom October through January if there is enough rain. Peak flowering occurs at the beginning of March through the end of April (Bowers and Dimmitt 1994). Cross-pollination is necessary to produce seed (U.S. Forest Service 2003). Brittlebush is a common landscaping plant both in residential and commercial areas in the Phoenix metropolitan area.

This study was conducted as part of a larger arthropod community experiment structured as a factorial nested design. Three land cover types were chosen: desert fringe, desert remnant, and mesiscaped urban. The desert fringe sites were typical creosote-dominated Sonoran desert community found in desert parks on the outskirts of the urbanized areas. Other plants in the community include mesquite shrubs (Prosopis spp.), palo verde shrubs (Parkinsonia spp.), cactus, herbaceous perennials, annuals, and brittlebush. The desert remnant sites had the same plant community structure of the desert fringe sites but were located in large desert parks $\left(>5 \mathrm{~km}^{2}\right)$ within the urban matrix. The mesiscaped urban sites were dominated by buildings providing shade, nearby impervious surfaces, trees, and grass and herbaceous cover. Three sites for each land cover type were chosen as replicates, for a total of nine sites (Figure 1). Sites were chosen randomly but were limited by the ability to obtain permits, where vandalism was a low risk, and where a water source was available. The three desert fringe sites were located in parks near the Phoenix metropolitan area (Usery Park, White Tanks, and Estrella Park). The three desert remnant sites were located in desert parks within the Phoenix metropolitan 


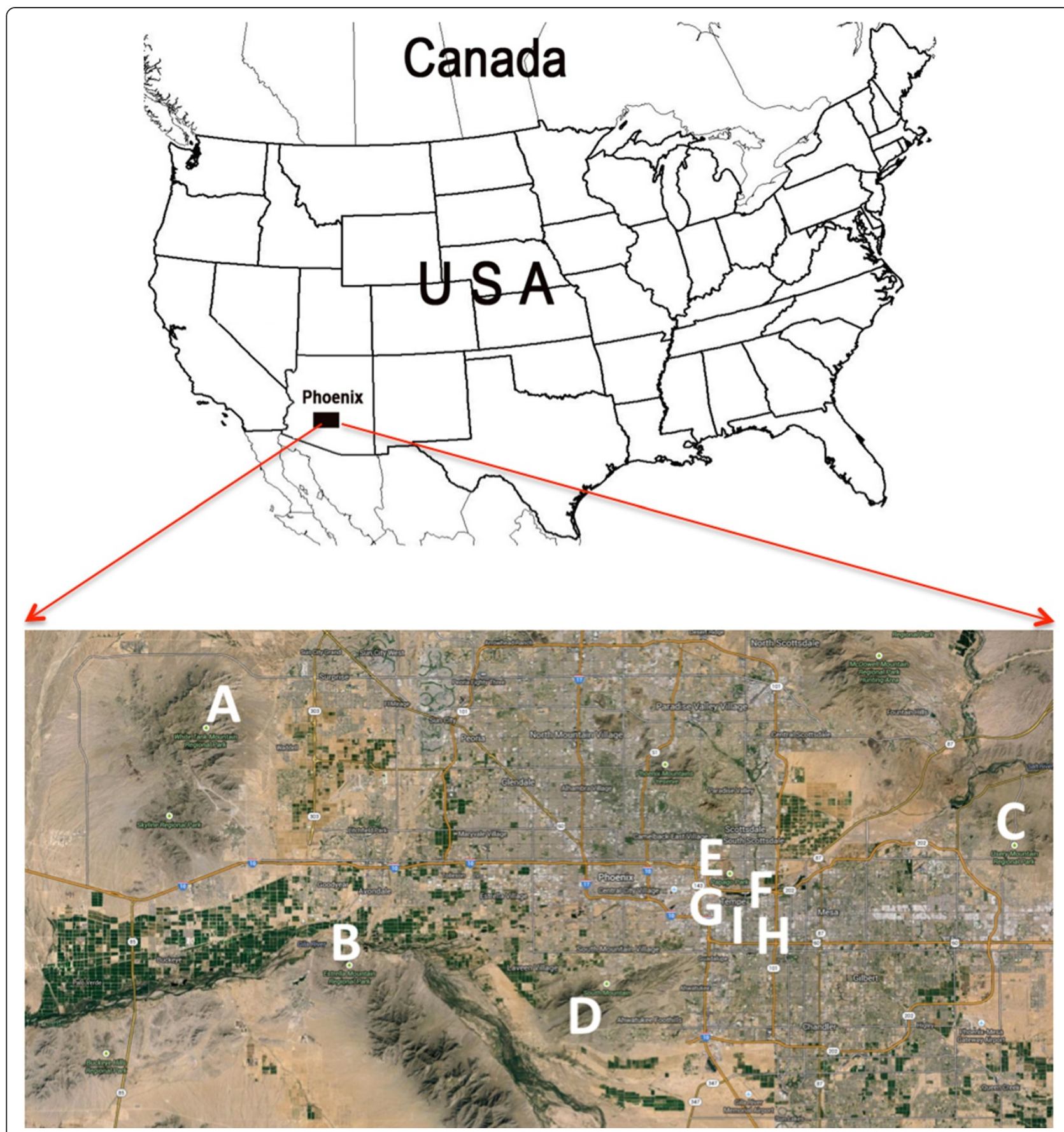

Figure 1 Map of sites across the Phoenix metropolitan area. (A) White Tanks, (B) Estrella Mountain, (C) Usery Park, (D) South Mountain Park, (E) Desert Botanical Garden, (F), Community Services Building, (G), Excelencia Elementary, (H) Meyer Elementary, and (I) Arizona State University-Tempe.

area (South Mountain Park, Desert Botanical Garden, and behind the Community Services Building, Arizona State University). The three mesiscaped urban sites were located within three school yards in the Phoenix metropolitan area (Meyer Elementary, Excelencia Elementary, and Arizona State University-Tempe).
Within each site, 60 genetically different (i.e., not cloned) potted, 5-gallon plants were placed on the ground within a fenced area. The 9- to 12-month-old plants, $43.6 \pm 11.2 \mathrm{~cm}$ in height (mean $\pm \mathrm{SD}$ ), were purchased from a local wholesale nursery and placed at the sites in the fall of 2006. There were holes in the bottom 
of the pots that allowed the roots to grow into the ground. Due to the intense sunlight in the Sonoran desert, each pot was covered with Reflectix ${ }^{\oplus}$ insulating material (Markleville, IN, USA), reflecting $97 \%$ of radiant heat. The soil in the pots contained a slow release fertilizer (Osmocote ${ }^{\oplus}$; 19-6-12 N-P-K).

\section{Methods}

Water was delivered individually to each plant through polyvinyl tubing, controlled by timers. All the plants received water on an optimal schedule (four times a week at $20 \mathrm{~min}$ once a day) until the water treatments were initiated the last week of November 2006. After that, one third of the plants (20) at each site were exposed to a low watering schedule (1 day/week), another third to a medium water treatment (2 days/week), and the rest (20) remained on the high water treatment (4 days/week). The plants received about $1.3 \mathrm{~L}$ per $20 \mathrm{~min}$ of watering, with some variation depending on local water pressure. In addition, the plants received ambient water from precipitation. Drip irrigation and sprinklers were turned off where the pots were located in the mesiscaped urban sites for the duration of the experiment. The water schedule was increased in early February, to compensate for lack of ambient water, but the differentiation between the treatments remained the same. Thus, across all land cover types, the plants received the exact same amount of water and had similar soil conditions.

Beginning 14 Feb. 2007 and ending 16 May 2007, all sites were visited once per week on the same day, for a total of 14 weeks. The presence or absence of flowers was recorded for each plant at each site. No data was collected during week 3; however, the presence of flowers the previous week was interpolated based on whether or not dried flowers were present. More frequent visits and counts of the number of flowers on each plant were not done due to time constraints. Data collection ended in May because this was when the water treatments ended and when the plants began to die because of the summer heat. Pots do not buffer temperature to protect plant roots as well as plants in the ground. Time to first flower, length of flowering, and percentage of plant flowering were calculated based on the presence/absence data collected each week from each plant.

Pan-trapping was used to collect potential pollinators from each site. Despite pan-trapping being considered inferior to netting and because of bias and underestimating abundance and richness (Cane et al. 2000), it enabled collection over a long period of time at many sites and prevented bias in individually netting 60 plants about 2 $\mathrm{ft}$ from each other. It was also used in a previous bee pollinator study conducted in the Phoenix metropolitan area (McIntyre and Hostetler 2001). Pan-trapping, even with one color, is sufficient to capture richness and abundance of bees (Stephen and Rao 2005; Toler et al. 2005), albeit these studies did not address non-bee pollinators.

Beginning 23 Mar. 2007 and ending 16 May 2007, all sites were visited twice per week on the same days, for a total of 9 weeks. On the first visit of each week, three plastic, 8-oz $(237 \mathrm{ml})$, yellow bowls were set out on the ground, in full sun, at semi-random spots at each site. Yellow bowls were chosen because brittlebush flowers are yellow. The bowls were filled to the brim with soapy tap water $(3 \mathrm{ml}$ unscented Ivory soap per gallon of water) and left out for $48 \mathrm{~h}$. The bowls were left out for $48 \mathrm{~h}$ to allow enough time to collect pollinators throughout the day, especially early morning, but not long enough to allow all of the water to evaporate. All bowls were set out between 7 a.m. and 2 p.m. On the second visit of each week, the contents of each bowl were collected into one glass jar per site in the same order as put out and within the same time frame. The same day the potential pollinators were collected, the soapy water was filtered and the arthropods were stored in 70\% ethanol for later identification. Data collection ended in May when the phenology observations ended.

Two-way ANOVA was used to test time to first flower and length of flowering using SPSS (ver. 15.01). Tukey HSD was used for post hoc comparisons. Kruskal-Wallis was used to test percentage of plants in flower using $R$ statistical software because these data were not normally distributed. Arthropods were identified to family (Triplehorn and Johnson 2005). Known pollinators of brittlebush (Mawdsley 2003; Moldenke 1976) were then separated out and analyzed. Univariate ANOVA was used to test overall abundance and richness and repeated measures ANOVA was used to test abundance and richness over time.

\section{Results}

\section{Brittlebush phenology}

Water treatment and land cover did not show an interaction effect for length of flowering $\left(F_{4,332}=1.3, p=0.269\right)$ or time to first flower $\left(F_{4,333}=1.6, p=0.184\right)$. We cannot say anything about interaction effects for percentage of plant in flower because we did not feel there was a good non-parametric analog of two-way ANOVA for this data set. Given there were no interaction effects, we analyzed marginal effects of water treatment and land cover. Water treatment did not result in significant differences in time to first flower $\left(F_{2,333}=1.7, p=0.190\right.$; Figure 2$)$, length of flowering $\left(F_{2,332}=0.4, p=0.692\right.$; Figure 2$)$, or percentage of plants in flower $\left(\chi^{2}=0.07, d f=2, p=0.9656\right)$.

However, land cover had a significant effect on the flowering phenology parameters measured. Brittlebush plants bloomed $17.4 \pm 0.3$ (mean $\pm \mathrm{SE}$ ) weeks after treatment began in mesiscaped urban sites, $15.0 \pm 0.4$ weeks 


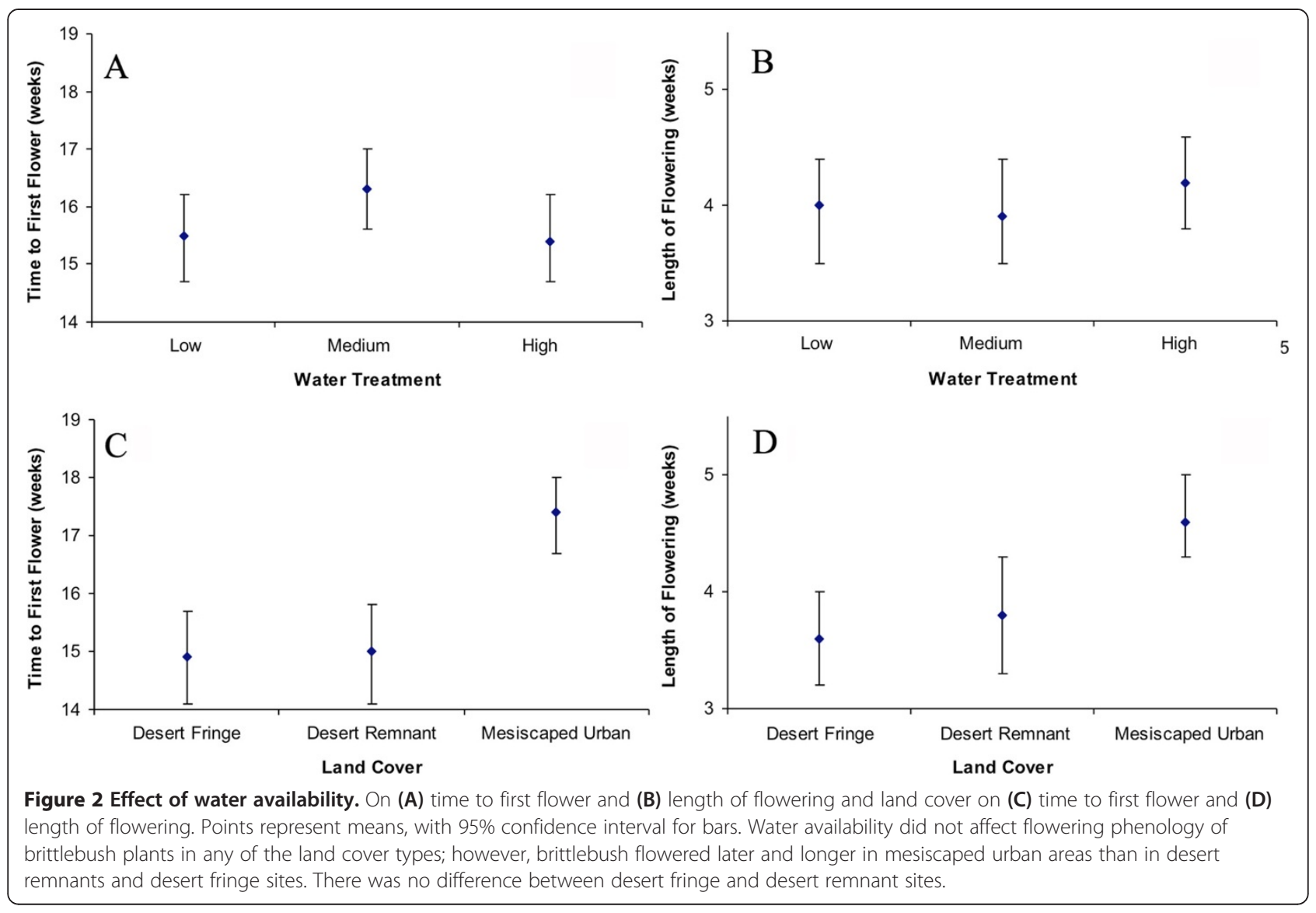

later in desert remnant sites, and $14.9 \pm 0.4$ weeks later in desert fringe sites. The means were not all equal $\left(F_{2,333}=16.7, p<0.001\right)$ : while there was not a significant difference between desert fringe and desert remnant sites $(p=0.956)$, mesiscaped urban sites were significantly different from both desert fringe and desert remnant sites $(p<0.001$; Figure 2). Furthermore, there was more variation in time to first flower in the desert fringe and desert remnant sites than in the mesiscaped urban sites.

Land cover also had a significant effect on mean length of flowering $\left(F_{2,332}=7.8, p<0.001\right)$. Brittlebush plants in mesiscaped urban sites bloomed an average of $4.6 \pm 0.2$ weeks, an average of $3.8 \pm 0.2$ weeks in desert remnant sites, and $3.6 \pm 0.2$ weeks in desert fringe sites. Plants in mesiscaped urban sites bloomed for a significantly longer period of time than those in desert remnant sites $(p=0.001)$ and those in desert fringe sites $(p=0.013)$; however, there was no difference in blooming period of plants in desert fringe and desert remnant sites $(p=0.823$; Figure 2).

Lastly, percentage of plants that bloomed was significantly different between the land cover types $\left(\chi^{2}=10.42\right.$, $d f=2, p=0.005)$. In mesiscaped urban sites, $87.2 \pm 2.8$ percent of brittlebush plants produced flowers, $48.9 \pm 11.3$ percent of plants in desert remnant sites produced flowers, and $53.3 \pm 6.4$ percent of plants in desert fringe sites produced flowers. There did not appear to be a significant difference in percent of plants that produced flowers in desert remnant and desert fringe sites; however, there appear were more plants that produced flowers in mesiscaped urban sites than in either desert remnant sites or desert fringe sites.

Brittlebush plants located in mesiscaped urban sites maintained the highest proportion of plants flowering throughout the observation period (Figure 3). However, plants in all sites peaked in flowering around weeks seven and eight (April). The proportion of plants in flower at mesiscaped urban sites appeared to decrease at a more rapid rate compared to brittlebush plants in desert remnant and desert fringe sites. Overlap in flowering time between desert remnant and desert fringe sites was complete but was only about 2 weeks between mesiscaped urban sites and the desert sites (Figure 4). The overlap was during the first 2 weeks and last 2 weeks, respectively.

\section{Pollinator abundance and richness}

Known pollinators of brittlebush from four orders and 13 families were collected from all sites over the course of the study. Known pollinators include Coleoptera 


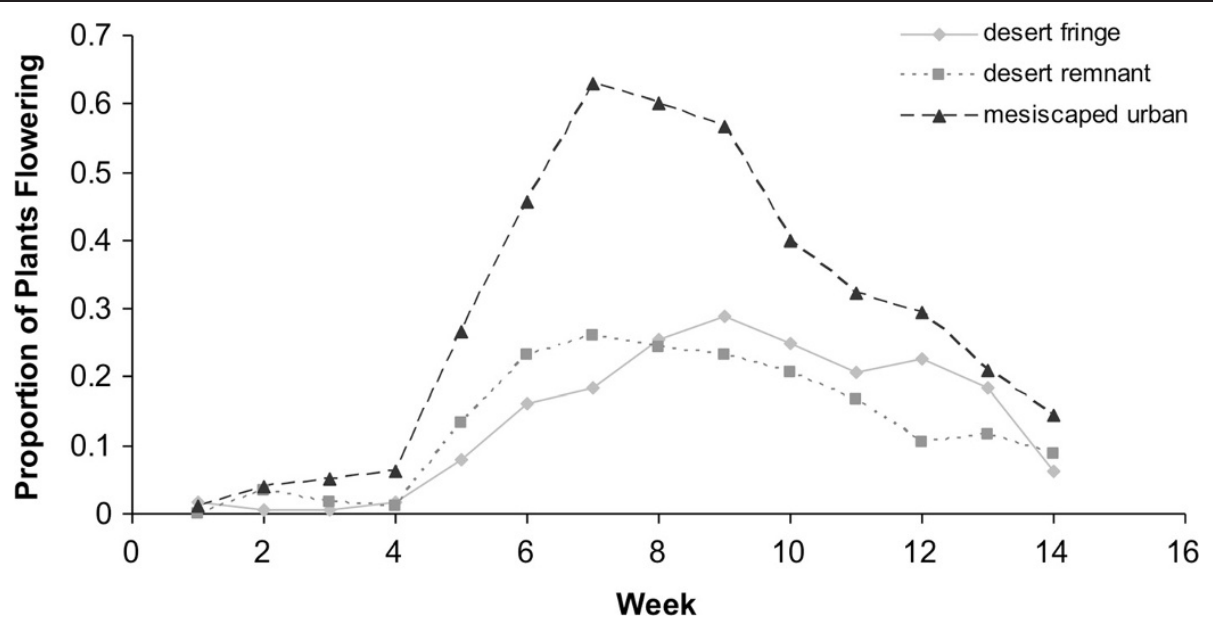

Figure 3 Proportion of brittlebush plants flowering each week by land cover. Time in weeks refers to when observations began on 14 February 2007. Plants at all land cover types peaked around 7 to 8 weeks after observations began; however, the mesiscaped urban sites had a higher proportion of plants flowering during the entire observation period.

(Coccinelidae, Melyridae, Meloidae), Diptera (Syrphidae, Tephritidae, Bombyliidae), Lepidoptera (Rhopalocera), and Hymenoptera (Apidae, Halictidae, Andrenidae, Megachilidae, Vespidae, and Sphecidae). Abundance in each land cover type was significantly different $\left(F_{2,6}=12.5, p=0.007\right.$; Table 1$)$. The total pollinator abundance collected from desert fringe sites was $594.3 \pm 65.8$ (mean \pm SE), $214.7 \pm 120.6$ from desert remnant sites, and $45.0 \pm 10.3$ from mesiscaped urban sites. Desert fringe sites had significantly higher pollinator abundance than either desert remnant or mesiscaped urban sites $(p<0.001)$. There was no significant difference between desert remnant and mesiscaped urban sites. Family richness also varied significantly by land cover type $\left(F_{2,6}=14.4, p=0.005\right)$. Desert fringe sites had significantly higher richness $(10.3 \pm 0.3)$ than mesiscaped urban sites $(4.7 \pm 1.3, p=0.006)$; but whereas there was no significant difference between desert remnant sites $(9.7 \pm 0.3)$ and desert fringe sites, there was a significant difference in richness compared to mesiscaped urban sites $(p=0.012)$. Percent similarity of families found in desert fringe and desert remnant sites was $80 \%, 61 \%$ in desert fringe and mesiscaped urban sites, and $55 \%$ in desert remnant and mesiscaped urban sites.

Of the four orders collected, only total hymenoptera abundance was significantly different among the land cover types $\left(F_{2,6}=63.7, p<0.001\right.$; Table 1$)$. From desert

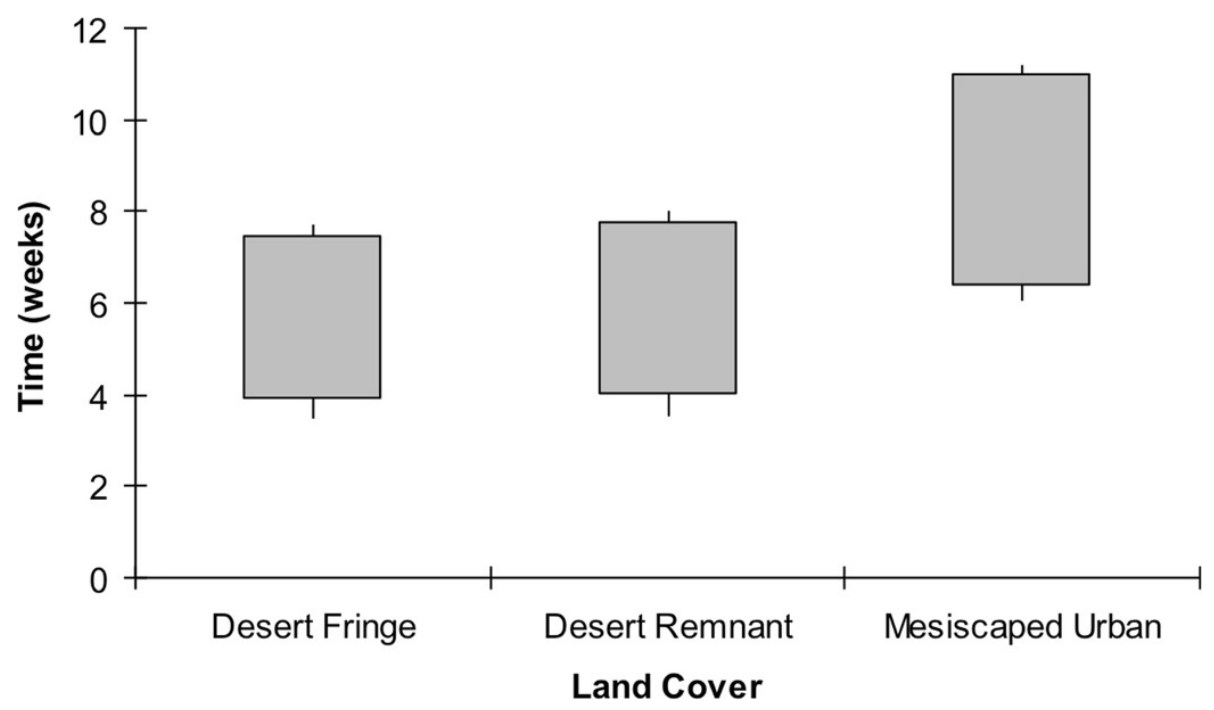

Figure 4 Average time of flowering of brittlebush for each land cover type. Bars represent mean start and length of flowering with standard error for error bars. There is complete overlap in flowering time between desert remnant and desert fringe sites; however, there is only about a 2-week overlap between plants at the desert sites and plants at the mesiscaped urban sites. Time based on when observations began. 
Table 1 Statistical values for abundance of potential pollinators

\begin{tabular}{|c|c|c|c|c|c|c|c|c|}
\hline \multirow[t]{2}{*}{ Order } & \multirow[t]{2}{*}{$F_{2,6}$} & \multirow[t]{2}{*}{$p$ value } & \multirow[t]{2}{*}{ Mean } & \multirow[t]{2}{*}{$95 \% \mathrm{Cl}$} & \multicolumn{4}{|c|}{ Post hoc comparisons between sites ( $p$ values) } \\
\hline & & & & & & DF & $\mathrm{DR}$ & $\mathrm{MU}$ \\
\hline \multirow[t]{3}{*}{ Hymenopetera } & 63.7 & $<0.001^{*}$ & 346.7 & 296.0 to 397.3 & DF & $x$ & $<0.001$ & $<0.001$ \\
\hline & & & 96.7 & 46.0 to 147.3 & $\mathrm{DR}$ & $x$ & $x$ & 0.164 \\
\hline & & & 34.3 & -16.3 to 85.0 & $\mathrm{MU}$ & $x$ & $x$ & $x$ \\
\hline \multirow[t]{3}{*}{ Diptera } & 1.1 & 0.384 & 91.3 & -19.2 to 201.8 & DF & $x$ & 0.483 & 0.483 \\
\hline & & & 15.3 & -95.2 to 125.8 & $\mathrm{DR}$ & $x$ & $x$ & 1.000 \\
\hline & & & 2.7 & -107.8 to 113.2 & $\mathrm{MU}$ & $x$ & $x$ & $x$ \\
\hline \multirow[t]{3}{*}{ Lepidoptera } & 1.0 & 0.422 & 0.3 & -0.1 to 0.8 & DF & $x$ & 0.483 & 0.483 \\
\hline & & & 0.0 & -0.5 to 0.5 & $\mathrm{DR}$ & $x$ & $x$ & 1.000 \\
\hline & & & 0.0 & -0.5 to 0.5 & $\mathrm{MU}$ & $x$ & $x$ & $x$ \\
\hline \multirow[t]{3}{*}{ Coleoptera } & 2.4 & 0.175 & 155.7 & 36.7 to 274.7 & DF & $x$ & 0.733 & 0.160 \\
\hline & & & 102.7 & -16.3 to 221.7 & $\mathrm{DR}$ & $x$ & $x$ & 0.409 \\
\hline & & & 8.0 & -110.0 to 127.0 & $\mathrm{MU}$ & $x$ & $x$ & $x$ \\
\hline \multicolumn{9}{|l|}{ Hymenoptera } \\
\hline \multirow[t]{3}{*}{ Megachilidae } & 6.6 & $0.031^{*}$ & 12.0 & 6.9 to 17.1 & DF & $x$ & 0.068 & $0.034^{*}$ \\
\hline & & & 3.7 & -1.4 to 8.8 & DR & $x$ & $x$ & 0.844 \\
\hline & & & 2.0 & -3.1 to 7.1 & $\mathrm{MU}$ & $x$ & $x$ & $x$ \\
\hline \multirow[t]{3}{*}{ Vespidae } & 0.4 & 0.729 & 0.3 & -0.5 to 1.1 & DF & $x$ & 0.768 & 1.000 \\
\hline & & & 0.7 & -0.1 to 1.5 & $\mathrm{DR}$ & $x$ & $x$ & 0.768 \\
\hline & & & 0.3 & -0.5 to 1.1 & $\mathrm{MU}$ & $x$ & $x$ & $x$ \\
\hline \multirow[t]{3}{*}{ Andrenidae } & 1.9 & 0.231 & 8.3 & -1.0 to 17.7 & DF & $x$ & 0.967 & 0.333 \\
\hline & & & 9.7 & 0.3 to 19.0 & $\mathrm{DR}$ & $x$ & $x$ & 0.250 \\
\hline & & & 0.0 & -9.3 to 9.3 & $\mathrm{MU}$ & $x$ & $x$ & $x$ \\
\hline \multirow[t]{3}{*}{ Halictidae } & 17.2 & $0.003^{*}$ & 261.3 & 188.5 to 334.1 & DF & $x$ & $0.010^{*}$ & $0.004^{*}$ \\
\hline & & & 74.0 & 1.2 to 146.9 & $\mathrm{DR}$ & $x$ & $x$ & 0.556 \\
\hline & & & 28.3 & -44.5 to 101.1 & $\mathrm{MU}$ & $x$ & $x$ & $x$ \\
\hline \multirow[t]{3}{*}{ Apidae } & 5.5 & $0.045^{*}$ & 8.0 & 4.0 to 12.0 & DF & $x$ & 0.128 & $0.043^{*}$ \\
\hline & & & 2.7 & -1.3 to 6.6 & DR & $x$ & $x$ & 0.676 \\
\hline & & & 0.7 & -3.3 to 4.6 & $\mathrm{MU}$ & $x$ & $x$ & $x$ \\
\hline
\end{tabular}

Only abundance in the hymenoptera order was significantly different between sites. The difference was due to the abundance of individuals in the Halictidae, Apidae, and Megachilidae families. DF, desert fringe, DR, desert remnant, and MU, mesiscaped urban.

*Statistically significant at the 0.05 level.

fringe sites, $346.7 \pm 8.8$ Hymenoptera individuals were collected; from desert remnant sites, $96.7 \pm 33.8$ individuals; and from mesiscaped urban sites, $34.3 \pm 8.2$. Hymenoptera total abundance was significantly higher in desert fringe sites than those in either desert remnant or mesiscaped urban sites $(p<0.001)$, but there was no significant difference between the desert remnant and mesiscaped urban sites. When the data was broken down by family, only three of the four bees (Halictidae, Apidae, and Megachilidae) demonstrated significant differences in total mean abundance among the land cover types (Table 1). The percentage of Coleoptera pollinators $\left(F_{2,6}=1.2, p=\right.$ $0.356)$, Hymenoptera pollinators $\left(F_{2,6}=1.7, p=0.261\right)$, Lepidoptera pollinators $\left(F_{2,6}=1.0, p=0.422\right)$, and Diptera pollinators $\left(F_{2,6}=0.56, p=0.598\right)$ was not significantly different between land cover types (Figure 5).

Mean abundance of pollinators did not change significantly over the course of the study but was consistently highest in desert fringe sites (Figure 6). An average of $66.0 \pm 19.8$ pollinators were caught each week in desert fringe sites, $23.8 \pm 6.3$ each week in desert remnant sites, and $5.0 \pm 1.5$ each week in mesiscaped urban sites. Weekly pollinator capture was significantly different between desert fringe and mesiscaped urban sites ( $p=$ 0.037). Furthermore, there was not a significant change in Coleoptera, Hymenoptera, Lepidoptera, or Diptera abundance over time. Richness varied significantly over time (Huynh-Feldt $F_{8}=3.1, p=0.007$ ), following a cubic 


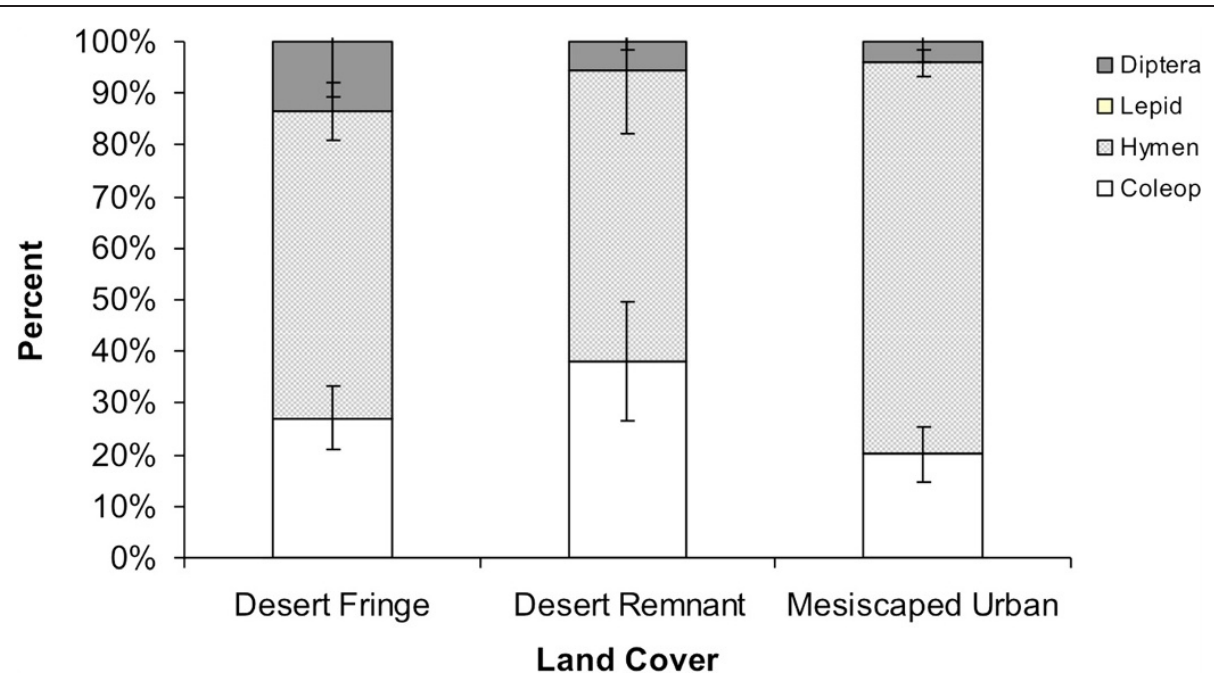

Figure 5 Percentage of pollinators categorized by order in each land cover type. The percentage of potential pollinators captured in all land cover types was not significantly different and was about 28\% Coleoptera, 63\% Hymenoptera, 7\% Diptera, and $<1 \%$ Lepidoptera. The bars are means for each land cover with standard error for error bars.
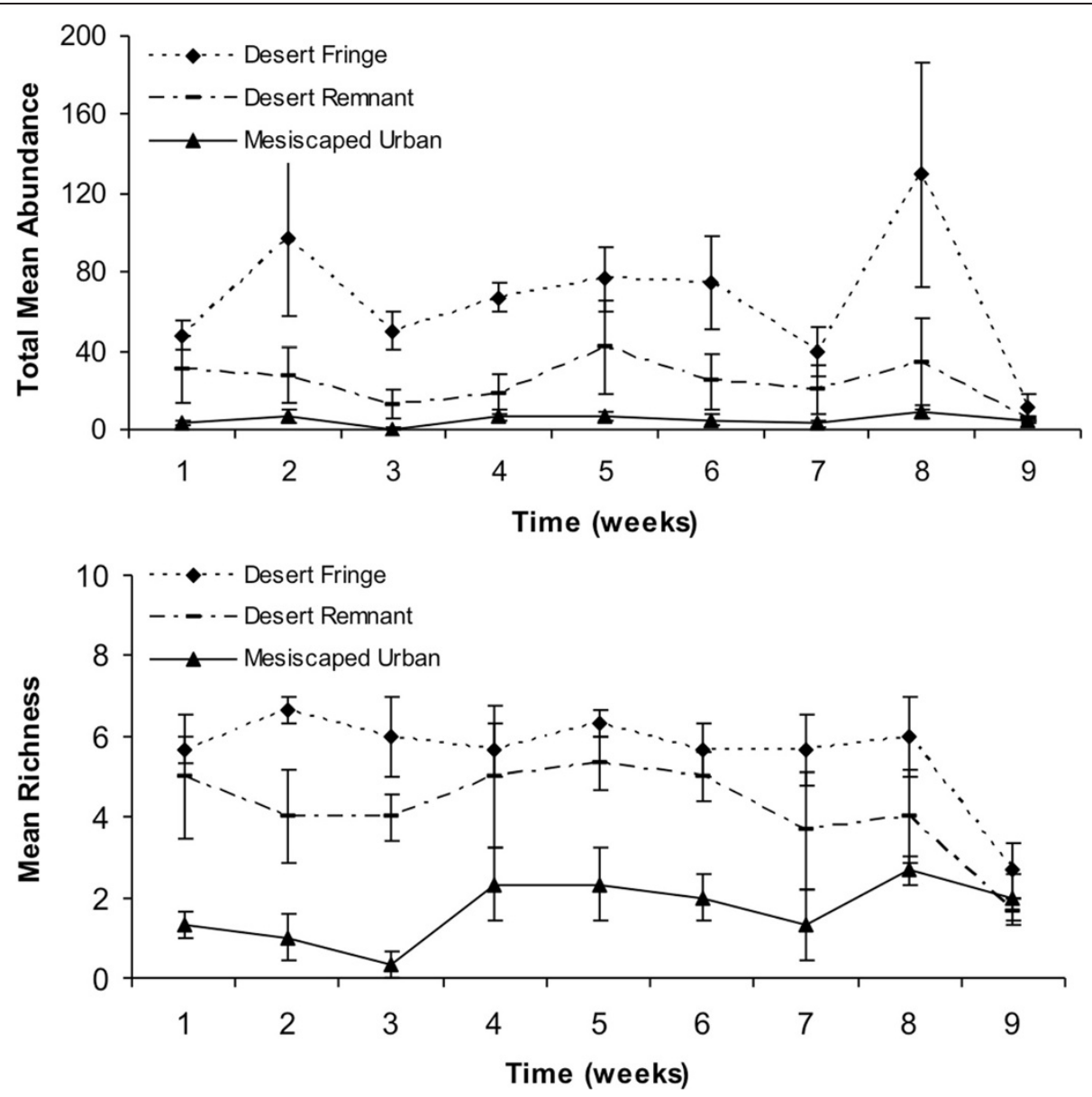

Figure 6 Pollinator abundance and richness over time at each land cover type. Richness, but not abundance, changed over the course of spring. Means for each land cover at each week with standard error for error bars. 
pattern $\left(F_{1}=15.9, p=0.007\right)$. Richness was consistently significantly higher in desert fringe sites $(5.6 \pm$ $0.7)$ compared to mesiscaped urban sites (1.7 \pm 0.4 ; $p=0.002$ ) but not significantly higher than desert remnant sites $(4.2 \pm 0.6)$. Hymenoptera abundance was consistently significantly higher $(38.5 \pm 12.2)$ in desert fringe sites compared to those in desert remnant sites $(10.7 \pm 2.3, p=0.039)$ and mesiscaped urban sites $(3.8 \pm 2.2, p<0.001)$. There was no significant difference between desert remnant and mesiscaped urban sites.

There was no correlation between pollinator abundance and proportion of brittlebush plants in flower; however, richness appeared to negatively correlate in mesiscaped urban land covers with increasing proportion of plants in flower (Figure 7).

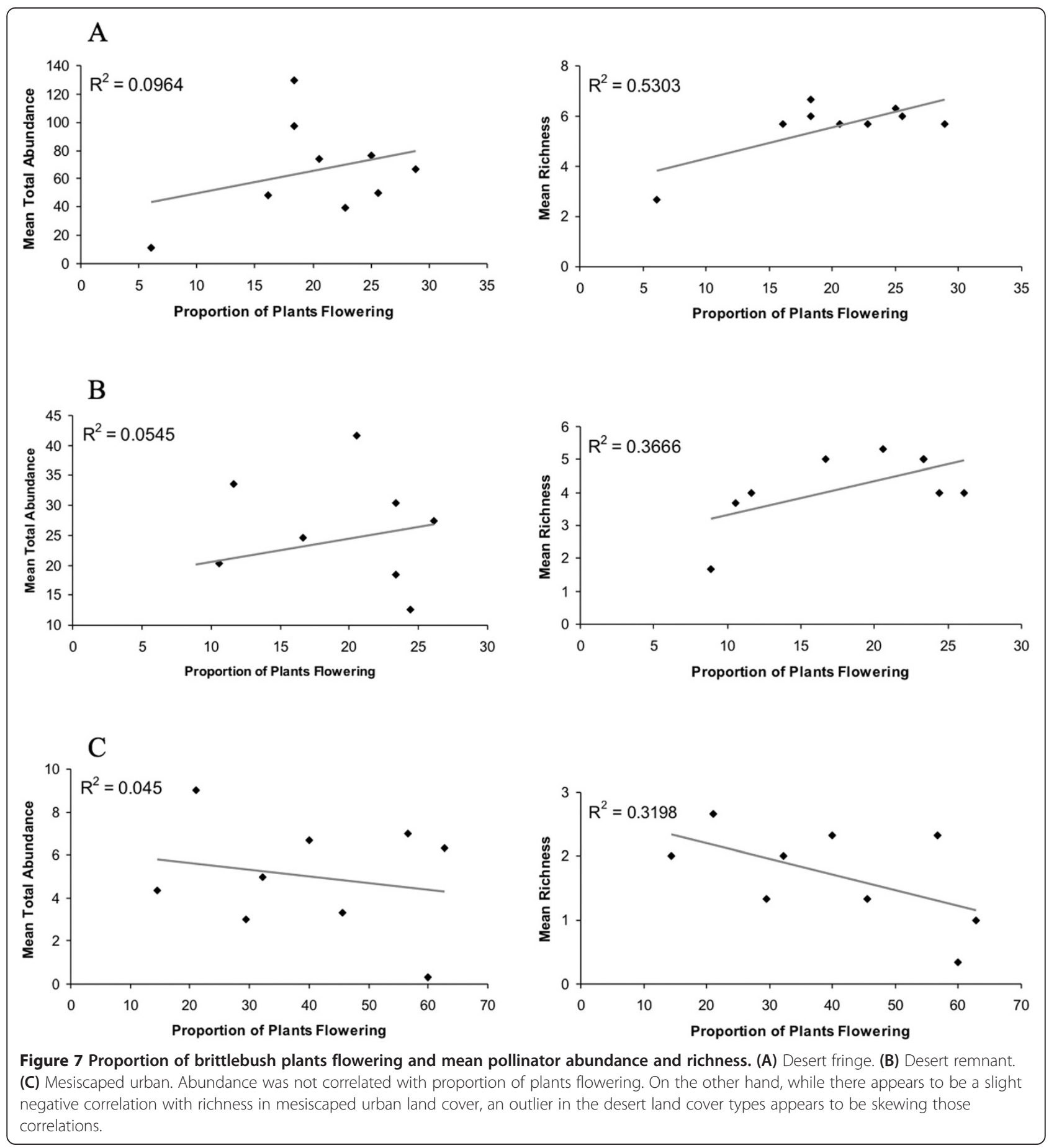




\section{Discussion and conclusions}

\section{Brittlebush flowering phenology}

Our results have shown that brittlebush plants in mesiscaped urban sites bloomed about 2.5 weeks later, one week longer, and at nearly twice the percentage of brittlebush plants in desert remnant and desert fringe sites. Our hypothesis that water treatment would produce differences in time to first flower, flowering time length, and percent of plants flowering did not appear supported by this study. However, land cover did produce significant differences. Our study partially agrees with the conclusions of Bowers and Dimmitt (1994) regarding the flowering phenology triggers of brittlebush. Bowers and Dimmitt (1994) determined that brittlebush flowering is triggered by cool season rains of at least $20 \mathrm{~mm}$ combined with a heat sum of $415^{\circ}$ days above $10^{\circ} \mathrm{C}$. Plants appear to need at least an additional $30 \mathrm{~mm}$ of rain to maintain flower production. The additional rain requirement likely accounts for the variability in duration of flowering from year to year. However, blooming in the desert is rare in the summer despite the summer rains. This appears to be due to high temperatures inhibiting development of flowers. Because of the apparent opportunistic nature of brittlebush to bloom when there is sufficient rain, constrained by high and low temperatures, Bowers and Dimmitt (1994) hypothesize that pollinators have not had a significant effect on the evolution of flowering phenology of brittlebush. What caused the patterns observed by us and the differences compared to previous studies?

First, the differences seen between land cover types may be due to temperature differences. Temperature was not measured at each of the sites; nonetheless, mesiscaped urban land cover with its greater amount of vegetation has been documented in the Phoenix metropolitan area as cooler than desert land cover (Balling and Brazel 1988; Martin and Stabler 2002; Mueller and Day 2005). According to these studies, commercial urban land cover types are about $2^{\circ} \mathrm{C}$ hotter and mesiscaped land cover types about $2^{\circ} \mathrm{C}$ cooler than desert land cover types. Our preliminary investigations revealed a similar pattern (unpublished data). The cooler temperatures may explain the delayed flowering time and the longer period of flowering of brittlebush in mesiscaped land cover types. It also may explain why there were no significant differences between desert remnant and desert fringe sites. Our results agree with Bowers and Dimmitt's (1994) contention that brittlebush has a degreeday heat requirement and that high temperatures truncate blooming period, but not the moisture requirement.

Second, we have two hypotheses for why a difference in flowering phenology was not seen between water availability treatments. The first hypothesis is that water availability is not as important as temperature in triggering and maintaining flowering in brittlebush. This seems unlikely due to the previous investigations on flowering phenology of brittlebush in particular and desert plants in general. The alternative hypothesis is that water availability is as important as temperature but not from the current year's precipitation. Rather, it could be water availability from precipitation during the previous fall or spring that is important. Studies on desert plant flowering and fruiting phenology (Crimmins et al. 2008; Friedel et al. 1993) indicate that many desert plants have a stronger correlation between flowering phenological events and precipitation from the previous year, usually fall. Further studies with brittlebush will need to not only maintain the plants over multiple years but also maintain the water treatments throughout the year.

\section{Brittlebush pollinator dynamics}

Potential pollinator richness, but not abundance, in desert remnant sites was significantly higher than mesiscaped urban sites and richness and abundance was significantly higher in desert fringe sites compared to mesiscaped urban sites. According to our results, the higher abundance in desert fringe sites is due to a higher abundance of bees. Moreover, the higher abundance of bees in desert fringe sites does not appear to significantly affect the percentage of pollinators that are bees in desert fringe sites.

In spite of the greater percentage and longer blooming of brittlebush in mesiscaped urban sites, there are relatively few pollinators present to pollinate them. The lower abundance may be a combination of low native vegetation species and diversity - which would explain why pollinator family richness is not less in desert remnant land cover types - (McIntyre and Hostetler 2001) and pollution (McFrederick et al. 2008). Additional studies need to examine pollination and reproductive success in the different land cover types. While number and density of brittlebush plants in the plot sites were constant across all land cover types, there are fewer brittlebush plants in urban landscapes than in desert remnants and fringe habitats. It would be interesting to test if pollinator abundance, land cover, or brittlebush plant density affect pollination or reproductive success of brittlebush (Cheptou and Avendano 2006) - particularly considering that brittlebush requires cross pollination (U.S. Forest Service 2003).

Our results agree with a previous study (McIntyre and Hostetler 2001) that bee abundance is lowest in mesiscaped urban land cover types. However, our study indicates that bee abundance is significantly lower in desert remnant land cover types than in desert fringe land cover types during spring whereas McIntyre and Hostetler (2001) found no significant differences between these two land cover types in April. These differing results may reflect differences in collection duration, as they collected over a 36 -h period in spring and in summer (September) in different land cover types (McIntyre and Hostetler 2001). Bees are considered the most important arthropod pollinators in the Sonoran 
desert and worldwide (McIntyre and Hostetler 2001; Simpson and Neff 1987), but as bee pollinator abundance and richness decreases in most urban land cover types (Cane et al. 2006; Eremeeva and Sushchev 2005; Matteson et al. 2008; McIntyre and Hostetler 2001; Tommasi et al. 2004), other arthropod pollinators, such as flies, butterflies, moths, beetles, and wasps may become more important. This is an area ripe for further investigation, in particular because our study indicates no significant difference in abundance of pollinators in these other orders. There is concern regarding arthropod pollinators in other orders and families (e.g., Syrphidae and Muscidae flies, solitary bees) effectively providing out-crossing pollination (Brunet and Sweet 2006), but large floral displays appear to positively affect the rate of out-crossing (Brunet and Sweet 2006). Other species of plants flowering at the same time and with the same color of flowers, as was observed by the authors, may enhance the rate of out-crossing.

\section{Brittlebush population and community dynamics in cities} The phenological and pollinator differences may affect population and community dynamics in urban ecosystems. There is overlap in blooming period between mesiscaped urban and desert sites, so there is still the potential for gene flow between these populations if brittlebush pollinators travel far enough. However, if pollinators do not travel far enough, then there is the potential for isolated genetic changes and the development of ecotypes (Franks et al. 2007). Furthermore, mesiscaped urban land cover types are significantly depauperate in abundance and richness of pollinators, which may also decrease the potential for gene flow. Because mesiscaped patches and desert remnant patches are scattered throughout the Phoenix metropolitan area, the spatiotemporal pattern of flowering and pollinator abundance and richness does not reflect an even gradient from the desert fringe to the urban core. This study indicates that the flowering pattern and pollinator community is much more heterogeneous across both space and time and that desert remnants appear to vary in their similarity of arthropod pollinators to surrounding native areas depending on community measurement. A multiyear investigation of flowering phenology patterns will help clarify the overall long-term effects of urbanization on patchiness of flowering.

The later blooming time of brittlebush in mesiscaped urban sites may limit pollen availability to pollinators on the front end but continues to provide pollen at the back end of spring. Because brittlebush is visited principally by generalist pollinators, this may not be a problem for the pollinators depending on flowering patterns of other plants in the community (Memmott et al. 2007). Blooming times of yellow-flowered creosote (Larrea tridentata, native), palo verde (Parkinsonia florida, native), P. microphylla (native), P. aculeata (non-native), P. praecox (non- native), many palo verde hybrids, and several non-woody ephemerals overlap the blooming period of brittlebush (personal observation). Nonetheless, our study does not indicate a significant change in synchronization between pollinator abundance and brittlebush flowering. Our results suggest that while brittlebush plants in desert fringe and desert remnant sites have lower flowering and more unpredictable flowering over the course of spring, they have more pollinators available. On the other hand, brittlebush plants in mesiscaped urban sites have more flowering that is more predictable but with much fewer pollinators available. Identifying the effective pollinators in each land cover type is the next step to better understanding the consequences of modified flowering phenology in plant and pollinator communities. Our study, and further research into pollinator effectiveness in urban land cover types, will better enable us to understand how reproductive dynamics in flowering plants are affected by the presence of pollinators over time and by the type of pollinators.

Flowering phenology responses of Sonoran desert plants to different land cover types are generally unpredictable because it is influenced by both constraints of the physical environment (water availability and temperature) and a mixed community of plants evolved from cool temperate and warm subtropical climates (Bowers and Dimmitt 1994). Thus, some plants are significantly affected by pollinator availability (e.g., ocotillo), some by seed production and germination during summer rains, and others just by abiotic physiological constraints. Studies of flowering phenology of additional plants (native and non-native), available pollinators throughout the year and in different land cover types (e.g., xeriscaped urban, mesiscaped urban, residential, commercial, parks, etc.), and genetic makeup of seeds produced in different land covers would elucidate the positive and negative population and community dynamic consequences of the changes hinted at in this brittlebush study. This study provides the first experimental evidence of what aspects of urbanization affect the flowering phenology of brittlebush and its pollinator community for the duration of flowering in a desert city.

\section{Competing interests}

The authors declare that they have no competing interests.

\section{Authors' contributions}

KN collected and analyzed data and drafted the manuscript. JW helped with the design of the study and writing of the manuscript. CB and SF helped with the design and coordination of the study. All authors read and approved the final manuscript.

\section{Acknowledgements}

The authors thank Tad Day, Leslie Landrum, Ms. Tseng, John Nagy, and the anonymous reviewers for their valuable comments. This research was in part supported by the National Science Foundation (NSF) under Grant No. DEB 0444228 and Grant No. DEB 9714833, Central Arizona-Phoenix Long-Term Ecological Research (CAP LTER). 


\section{Author details}

${ }^{1}$ School of Life Sciences, Arizona State University, P.O. Box 874501, Tempe, AZ 85287-4501, USA. ${ }^{2}$ School of Sustainability, Global Institute of Sustainability, Arizona State University, Tempe, AZ 85287, USA. ${ }^{3}$ Department of Biology, University of North Carolina-Greensboro, Greensboro, NC 27402, USA.

\section{Received: 15 April 2014 Accepted: 14 June 2014}

Published online: 22 August 2014

\section{References}

Arizmendi MD, Constanza MS, Lourdes J, Ivonne FM, Edgar LS (2007) Effect of the presence of nectar feeders on the breeding success of Salvia mexicana and Salvia fulgens in a suburban park near Mexico City. Biol Conserv 136:155-158

Balling RC, Brazel SW (1988) High-resolution surface temperature patterns in a complex urban terrain. Photogramm Eng Rem S 54:1289-1293

Bowers JE, Dimmitt MA (1994) Flowering phenology of six woody-plants in the northern Sonoran desert. B Torrey Bot Club 121:215-229

Brunet J, Sweet HR (2006) Impact of insect pollinator group and floral display size on outcrossing rate. Evolution 60:234-246

Buyantuyev A, Gries C, Wu J (2010) Multiscale analysis of the urbanization pattern of the phoenix metropolitan landscape of USA: time, space and thematic resolution. Landscape and urban planning. Landscape Urban Plan 94:206-217

Buyantuyev A, Wu J (2009) Urbanization alters spatiotemporal patterns of ecosystem primary production: a case study of the Phoenix metropolitan region, USA. J Arid Environ 73:512-520

Calvino-Cancela M (2006) Time-activity budgets and behaviour of the Amazilia hummingbird, Amazilia amazilia (Apodiformes:Trochilidae) in an urban environment. Rev Biol Trop 54:873-878

Cane JH, Minckley RL, Kervin LJ (2000) Sampling bees (Hymenoptera:Apiformes) for pollinator community studies: pitfalls of pan-trapping. J Kansas Entomol Soc 73:225-231

Cane JH, Minckley RL, Kervin LJ, Roulston TH, Williams NM (2006) Complex responses within a desert bee guild (Hymenoptera:Apiformes) to urban habitat fragmentation. Ecol Appl 16:632-644

Cheptou PO, Avendano LG (2006) Pollination processes and the Allee effect in highly fragmented populations: consequences for the mating system in urban environments. New Phytol 172:774-783

Crimmins TM, Crimmins MA, Bertelsen D, Balmat J (2008) Relationships between alpha diversity of plant species in bloom and climatic variables across an elevation gradient. Int J Biometeorol 52:353-366

Epple AO (1995) A Field Guide to the Plants of Arizona. The Globe Pequot Press, Connecticut

Eremeeva NI, Sushchev DV (2005) Structural changes in the fauna of pollinating insects in urban landscapes. Russ J Ecol 36:259-265

Fitter AH, Fitter RSR (2002) Rapid changes in flowering time in British plants. Science 296:1689-1691

Franks SJ, Sim S, Weis AE (2007) Rapid evolution of flowering time by an annual plant in response to a climate fluctuation. Proc Natl Acad Sci U S A 104:1278-1282

Friedel MH, Nelson DJ, Sparrow AD, Kinloch JE, Maconochie JR (1993) What induces central Australian arid zone trees and shrubs to flower and fruit? Aust J Bot 41:307-319

Gordo O, Sanz JJ (2005) Phenology and climate change: a long-term study in a Mediterranean locality. Oecologia (Berlin) 146:484-495

Grimm N, Faeth S, Golubiewski N, Redman C, Wu J, Bai X, Briggs J (2008) Global change and the ecology of cities. Science 319:756-760

Hepper FN (2003) Phenological records of English garden plants in Leeds (Yorkshire) and Richmond (Surrey) from 1946 to 2002. An analysis relating to global warming. Biodivers Conserv 12:2503-2520

Honour SL, Bell JNB, Ashenden TW, Cape JN, Power SA (2009) Responses of herbaceous plants to urban air pollution: effects on growth, phenology and leaf surface characteristics. Environ Pollution 157:1279-1286

Jenerette GD, Wu JG (2001) Analysis and simulation of land-use change in the central Arizona-Phoenix region, USA. Landscape Ecol 16:611-626

Lu PL, Yu Q, Liu JD, Lee XH (2006) Advance of tree-flowering dates in response to urban climate change. Agr Forest Meteorol 138:120-131

Luck M, Wu JG (2002) A gradient analysis of urban landscape pattern: a case study from the Phoenix metropolitan region, Arizona, USA. Landscape Ecol 17:327-339
Martin CA, Stabler LB (2002) Plant gas exchange and water status in urban desert landscapes. J Arid Environ 51:235-254

Matteson KC, Ascher JS, Langellotto GA (2008) Bee richness and abundance in New York City urban gardens. Ann Entomol Soc Am 101:140-150

Mawdsley JR (2003) The importance of species of Dasytinae (Coleoptera: Melyridae) as pollinators in western North America. Coleopts Bull 57:154-160

McFrederick QS, Kathilankal JC, Fuentes JD (2008) Air pollution modifies floral scent trails. Atmos Environ 42:2336-2348

McFrederick QS, LeBuhn G (2006) Are urban parks refuges for bumble bees Bombus spp. (Hymenoptera:Apidae)? Biol Conserv 129:372-382

Mclntyre NE, Hostetler ME (2001) Effects of urban land use on pollinator (Hymenoptera:Apoidea) communities in a desert metropolis. Basic Appl Ecol 2:209-218

Memmott J, Craze PG, Waser NM, Price MV (2007) Global warming and the disruption of plant-pollinator interactions. Ecol Lett 10:710-717

Mimet A, Pellissier V, Quenol H, Aguejdad R, Dubreuil V, Roze F (2009) Urbanisation induces early flowering: evidence from Platanus acerifolia and Prunus cerasus. Int J of Biometeorol 53:287-298

Moldenke AR (1976) California USA pollination ecology and vegetation types. Phytologia 34:305-361

Mueller EC, Day TA (2005) The effect of urban ground cover on microclimate, growth and leaf gas exchange of oleander in Phoenix, Arizona. Int J Biometeorol 49:244-255

Neil K, Landrum L, Wu J (2010) Effects of urbanization on flowering phenology in the metropolitan Phoenix region of USA: findings from herbarium records. J Arid Environ 74:440-444

Neil K, Wu J (2006) Effects of urbanization on plant flowering phenology: a review. Urban Ecosystems 9:243-257

Parmesan C (2006) Ecological and evolutionary responses to recent climate change. Annu Rev Ecol Evol S 37:637-669

Pauw A (2007) Collapse of a pollination web in small conservation areas. Ecology 88:1759-1769

Primack D, Imbres C, Primack RB, Miller-Rushing AJ, Del Tredici P (2004) Herbarium specimens demonstrate earlier flowering times in response to warming in Boston. Am J Bot 91:1260-1264

Roetzer T, Wittenzeller M, Haeckel H, Nekovar J (2000) Phenology in central Europe - differences and trends of spring phenophases in urban and rural areas. Int J Biometeorol 44:60-66

Schwartz MD, Reiter BE (2000) Changes in North American spring. Int I Climatol 20:929-932

Simpson BB, Neff JL (1987) Pollination Ecology in the Arid Southwest USA. Aliso $11: 417-440$

Stephen WP, Rao S (2005) Unscented color traps for non-Apis bees (Hymenoptera: Apiformes). J Kansas Entomol Soc 78:373-380

Toler TR, Evans EW, Tepedino VJ (2005) Pan-trapping for bees (Hymenoptera: Apiformes) in Utah's West Desert: the importance of color diversity. Pan-Pac Entomol 81:103-113

Tommasi D, Miro A, Higo HA, Winston ML (2004) Bee diversity and abundance in an urban setting. Can Entomol 136:851-869

Triplehorn CA, Johnson NF (2005) Borror and DeLong's Introduction to the Study of Insects. Thomson Brooks/Cole, Belmont, CA

U.S. Forest Service (2003) Encelia farinosa. In: vol. 2008.

Walther GR, Post E, Convey P, Menzel A, Parmesan C, Beebee TJC, Fromentin JC, Hoegh-Guldberg O, Bairlein F (2002) Ecological responses to recent climate change. Nature 416:389-395

Wu J, Jenerette G, Buyantuyev A, Redman C (2010) Quantifying spatiotemporal patterns of urbanization: the case of the two fastest growing metropolitan regions in the United States. Ecol Complex 8:1-8

Zhao TT, Schwartz MD (2003) Examining the onset of spring in Wisconsin. Clim Res 24:59-70

Ziska LH, Gebhard DE, Frenz DA, Faulkner S, Singer BD, Straka JG (2003) Cities as harbingers of climate change: common ragweed, urbanization, and public health. J Allergy Clin Immun 111:290-295

\section{doi:10.1186/s13717-014-0017-6}

Cite this article as: Neil et al:: Urbanization affects plant flowering phenology and pollinator community: effects of water availability and land cover. Ecological Processes 2014 3:17. 